\title{
The determination of the pain beliefs of the students at Akdeniz University Vocational School of Health Services
}

\author{
Hatice Gül ${ }^{1, a}$ and Suat Erel $^{2}$ \\ ${ }^{1}$ Akdeniz University Vocational School of Health Services, Antalya, Turkey \\ ${ }^{2}$ Pamukkale University School of Physiotherapy and Rehabilitation, Denizli, Turkey
}

\begin{abstract}
The purpose of this study is to determine the pain beliefs of Akdeniz University Vocational School of Health Services (AUVSHS) students. Fifty Physiotherapy Assistants students, 54 Paramedic students and 37 Elderly Care students who take pain education in their curriculum and 50 Child Development and Care students who do not take pain education were included in this study. The pain beliefs of the students were evaluated with Pain Beliefs Questionnaire. There was no statistically significant difference between organic (OBS) and psychological pain belief scores (PBS) of programs with and without pain education ( $p>0,05)$. There was statistically significant difference between OBS and PBS in favor of PBS in all programs $(p<0,05)$. In conclusion, it was determined that pain beliefs in AUVSHS were similar in all programs. It is important to balance between organic and psychological pain beliefs. So we plan to develop new training strategies to balance student's pain beliefs.
\end{abstract}

Keywords: Pain; organic pain beliefs; psycholological pain beliefs; students

\section{Introduction}

"Pain is a subjective, unpleasant sensory and an emotional experience that can reflect a real or potential physical injury" [1]. Acute pain is defined as a type of pain that lasts less than 3 months or the pain that is related to tissue damage. Chronic pain can be defined as pain that persists beyond normal tissue healing time and lasts more than 3 months $[2,3]$. Chronic pain is influenced by physical, cognitive, behavioral and psychological factors.

There are studies in the literature evaluating pain related beliefs in individuals with chronic pain [4-6]. Several studies have demonstrated that beliefs of the patients about the cause of their pain affect treatment compliance and outcome of treatment [7,8]. It was found that organic pain beliefs were approved by chronic pain patient more frequently than healthy persons [9]. It was determined that pain beliefs based on organic nature of pain lead to increase patient's physical dysfunction and decrease coping strategies [10-12].

We educate the student who serves in medical facilities in future. Thinking that only patient's beliefs are a problem for treatment would be wrong. Beliefs of healthcare

\footnotetext{
${ }^{\text {a }}$ Corresponding author: haticegul@akdeniz.edu.tr
} 
professionals could also affect the treatment outcome and cause to conflicts with patients $[13,14]$. Traditional pain education model in medical school associate the health of tissue to pain generally. This pain explanation model called as biomedical model may be helpful to clarify the pathoanatomic cause of injury in acute, subacute or perioperative conditions, but do not be helpful to clarify the cause of the chronic condition [15]. Because the health of tissue does not correlate with pain in chronic condition $[16,17]$.

The beliefs of the patient and healthcare professional get together during therapetic approaches. This meeting defined as therapeutic encounter described as a complex process of negotiations. The collaboration develops between patient and healthcare professional after negotiation. The healthcare professional who have a good knowledge and appropriate belief about pain process will be successful in collaboration with the patient [18].

In our study we want to investigate the beliefs of our student regarding organic and psychological nature of pain. Also we want to compare the pain beliefs of different programs which received and did not receive education about pain.

\section{Method}

The present study is a descriptive study that evaluates pain beliefs of the students at Akdeniz University Vocational School of Health Services. The Akdeniz University Clinical Research Ethics Committee gave approval for the present study (272/11.04.2018).

\subsection{Participant}

191 students were included in this study. Fifty Physiotherapy Assistants students, 54 Paramedic students and 37 Elderly Care students who took pain education in their curriculum and 50 Child Development and Care students who did not take pain education were participated in this study.

\subsection{Procedure}

Socio-demographic characteristics of students such as age, sex, past pain experience were saved. The pain beliefs of students were evaluated with Pain Beliefs Questionnaire (PBQ). The PBQ was developed as 20 items questionnaire and then reduced to 12 items. The questionnaire includes two scales, the Organic Beliefs Scale (8 items), and Psychological Beliefs Scale (4 items). Organic Beliefs Scale addresses organic nature of pain and deals with perceived cause of the pain. Psychological Beliefs Scale addresses the effect of psychological factors such as anxiety, depression and relaxation on pain. Each item is scored with 6 point ("always" to "never") scale. The PBQ organic and psychological subscales scores were obtained with calculation of the items score for each scale [4]. This questionnaire has been used successfully with chronic back pain $[5,9,19]$. But it is not necessary for a respondent to be in pain. This questionnaire could applied to healthy persons. It was determined that the Turkish version of PBQ is valid and reliable [20].

\subsection{Statistical Analysis}

SPSS for Windows 21.00 computer package program was used for all statistical analyses. Descriptive statistics were shown as the mean and standard deviation $(\mathrm{X} \pm \mathrm{SS})$ in the table. Mann Whitney-U test was used to compare organic and psychological pain beliefs between groups. Wilcoxon-signed test was used to compare organic and psychological pain beliefs within group. 


\section{Findings}

191 students were participated in this study. The mean age of the students was $20,30 \pm 2,25$ years. Also 150 students $(\% 78,5)$ were female and 41 students $(\% 21,5)$ were male in this study. One hundred fifty-five $(\% 81,2)$ students did not have past pain experience and 34 students $(\% 18,8)$ had past pain experience in this study. A large number of the students who had past pain experience were from the Child Development and Care program. The mean pain duration of the participants was $11,52 \pm 13,96$ months.

The mean organic belief score of Physiotherapy Assistants students was 4,29 $\pm 0,62$ and the mean psychological belief score of Physiotherapy Assistants students was 4,85 00,74 . The mean organic belief score of Paramedic students was 4,00 $\pm 0,72$ and the mean psychological belief score of Paramedic students was $4,56 \pm 0,89$. The mean organic belief score of Elderly Care students was 4,20 $\pm 0,64$ and the mean psychological belief score of Elderly Care students was $4,75 \pm 0,77$. The mean organic beliefs score of Child Development and Care students was 4,01 $\pm 0,67$ and the mean psychological beliefs score of Child Development and Care students was $4,47 \pm 0,93$. According to results, there was a statistically significant difference between Organic Beliefs Scale and Psychological Beliefs Scale in favor of Psychological Beliefs Scale in all programs $(p<0,05)$ (Table 1).

Table 1. Organic and psychological pain belief scores within groups comparison

\begin{tabular}{|l|l|l|c|c|}
\hline Groups & $\begin{array}{c}\text { Organic Pain } \\
\text { Beliefs Score } \\
\mathrm{X} \pm \mathrm{SS}\end{array}$ & $\begin{array}{c}\text { Pscychological } \\
\text { Pain Beliefs Score } \\
\mathrm{X} \pm \mathrm{SS}\end{array}$ & $\mathrm{z}$ & $\mathrm{p}^{*}$ \\
\hline Physiotherapy Asistant Students $(\mathrm{n}=50)$ & $4,29 \pm 0,62$ & $4,85 \pm 0,74$ & $-4,377$ & $\mathbf{0 , 0 0 0} *$ \\
\hline Paramedic students $(\mathrm{n}=54)$ & $4,00 \pm 0,72$ & $4,56 \pm 0,89$ & $-4,233$ & $\mathbf{0 , 0 0 0} *$ \\
\hline Elderly Care Student $(\mathrm{n}=37)$ & $4,20 \pm 0,64$ & $4,75 \pm 0,77$ & $-3,489$ & $\mathbf{0 , 0 0 0}$ \\
\hline Child Development and Care students $(\mathrm{n}=50)$ & $4,01 \pm 0,67$ & $4,47 \pm 0,93$ & $-2,831$ & $\mathbf{0 , 0 0 5}$ \\
\hline
\end{tabular}
${ }^{*} \mathrm{p}<0,05$

There was no statistically significant difference between organic and psychological pain belief scores of the students who took pain education and did not take pain education $(\mathrm{p}>0,05)$. (Table 2).

Table 2. Organic and psychological pain beliefs score between groups which took pain education and did not take pain education.

\begin{tabular}{|l|c|c|c|c|}
\hline Pain Beilefs Questionnaire & $\begin{array}{c}\text { Took pain } \\
\text { education }(\mathrm{n}=141)\end{array}$ & $\begin{array}{c}\text { Did not take pain } \\
\text { education }(\mathrm{n}=50)\end{array}$ & $\mathrm{z}$ & $\mathrm{p}^{*}$ \\
\hline Organic Pain Beliefs Score $\mathrm{X} \pm \mathrm{SS}$ & $4,15 \pm 0,67$ & $4,01 \pm 0,67$ & $-1,194$ & 0,232 \\
\hline Pscychological Pain Beliefs Score $\mathrm{X} \pm \mathrm{SS}$ & $4,71 \pm 0,81$ & $4,47 \pm 0,93$ & $-1,503$ & 0,133 \\
\hline
\end{tabular}

There was no statistically significant difference between Organic Beliefs Scale and Psychological Belief Scale of the students who had past pain experience and did not have past pain experience $(\mathrm{p}>0,05)$ (Table 3$)$.

Table 3. Organic and psychological pain beliefs score between groups which had past pain experience and did not have past pain experience.

\begin{tabular}{|l|c|c|c|c|}
\hline \multirow{2}{*}{ Pain Beilefs Questionnaire } & \multicolumn{2}{|c|}{ Past Pain Experience } & \multirow{2}{*}{ z } & \\
\cline { 2 - 3 } & Yes $(\mathrm{n}=34)$ & No $(\mathrm{n}=155)$ & & \\
\hline Organic Beliefs Score $\mathrm{X} \pm \mathrm{SS}$ & $4,06 \pm 0,73$ & $4,13 \pm 0,66$ & $-0,615$ & 0,539 \\
\hline Pscychological Beliefs Score $\mathrm{X} \pm \mathrm{SS}$ & $4,67 \pm 0,80$ & $4,64 \pm 0,86$ & $-0,047$ & 0,962 \\
\hline
\end{tabular}

There was no statistically significant difference between Organic Beliefs Scale and Psychological Belief Scale of the male and female students ( $>0,05)$ (Table 4). 
Table 4. Organic and psychosocial pain beliefs score between female and male students.

\begin{tabular}{|l|c|c|c|c|}
\hline \multirow{2}{*}{ Pain Beilefs Questionnaire } & \multicolumn{2}{|c|}{ Gender } & \multirow{2}{*}{$\mathrm{z}$} & \\
\cline { 2 - 3 } & Female $(\mathrm{n}=150)$ & Male $(\mathrm{n}=41)$ & & \\
\hline Organic Beliefs Score $\mathrm{X} \pm \mathrm{SS}$ & $4,08 \pm 0,69$ & $4,24 \pm 0,59$ & $-1,328$ & 0,184 \\
\hline Pscychological Beliefs Score $\mathrm{X} \pm \mathrm{SS}$ & $4,65 \pm 0,87$ & $4,63 \pm 0,78$ & $-0,498$ & 0,618 \\
\hline
\end{tabular}

${ }^{*} \mathrm{p}<0,05$

\section{Discussions and Conclusions}

In the present study, we searched pain beliefs of the students at Akdeniz University Vocational School of Health Services. For this purpose, we applied the Pain Beliefs Questionnaire to 191 students.

There were a few studies in the literature which use PBQ to examine pain beliefs of patients with chronic pain and students at university. It was determined that organic pain beliefs of chronic pain patient were stronger than their psychological belief $[5,19,21]$. There was no study which compare organic and psychological pain beliefs of students. But there was a study which correlate organic pain beliefs and psychological pain beliefs of the student. In this study it was found that there was a negative and weak correlation between organic and psychological pain beliefs of students [22]. In the present study we compared organic and psychological pain beliefs of our student. According to our results, it was determined that psychological beliefs of our students were stronger than their organic beliefs. In the study which determined that psychological beliefs of nonclinical sample is stronger than their organic beliefs was found same result with us [5]. We think that this result cannot be relevant to our education strategies. Even so this is an important finding because beliefs related organic nature of pain cause to use fearful terminology to patient during medical application of healthcare professional. This fearful terminology could increase patient's fear. On the other hand, it is important to provide the balance between organic and psychological pain beliefs of students. Because organic beliefs come to prominence during acute care, psychological beliefs come to prominence during chronic pain treatment. Physiotherapy assistant students, Paramedic students and Elderly Care students serve both in acute and chronic care period.

It was determined that pain beliefs in Akdeniz University Vocational School of Health Services were similar in all programs regardless of pain education situation. We couldn't decide whether the education of pain affect or does not affect the pain beliefs of our students. Because we didn't evaluate pain knowledge and past pain education model of our students. There is a questionnaire in literature which evaluate pain knowledge and is named as Neurophysiology of Pain Questionnaire. But we could not use this questionnaire because the Turkish version of this questionnaire haven't been validated yet.

It is recommended that professionals should receive education based on the biopsychosocial model and should know how to integrate it to care of patients [23]. Five studies assessed the effect of educational interventions that aimed to change pain beliefs of rehabilitation professionals and beliefs of students toward pain [24-28]. So we are planning to balance organic and psychological pain beliefs of students by developing new education strategies which based on pain neurophysiology education. Pain Neurophysiology Education program increase knowledge and beliefs about pain's biopsychosocial nature.

In the literature, it was determined that organic beliefs of female students were stronger than male students in nonclinical sample [22]. In our study it was determined that pain beliefs of students did not change in relation to gender. In a study it was found that organic beliefs of individuals who had past pain experience stronger than individuals who did not have past pain experience [5]. In our study we did not find any difference between the 
groups which had past pain experience and who did not. We think that this findings related to our young sample and unequal sample size.

In conclusion, the findings of this study show that psychological pain beliefs of our students stronger than organic pain beliefs. The level of pain knowledge of the students should be determined in future. We believe that beliefs affect from knowledge. Therefore, education of the students should consist of knowledge about pain based on biopsychosocial perspective. Also this education model should support organic and psychological pain beliefs of students. We believe that this perspective improves the efficacy of treatment.

\section{References}

1. International Association for the Study of Pain. IASP Taxonomy 2014 Available from: http://www.iasp-pain.org. [2016].

2. H. Merksey, N. Bogduk.. Classification of chronic pain (2nd ed.) [Seattle: IASP Press 1994].

3. P.S. Wall, R Melzack. Textbook of Pain (5th edn ed.) [ London:Elsevier 2005].

4. D.A Walsh, J.C Radcliffe. Pain beliefs and perceived physical disability of patients with chronic low back pain. Pain, 97, 23-31 [2002].

5. A.J.Baird, R.A. Haslam. Exploring differences in pain beliefs within and between a large nonclinical (workplace) population and a clinical (chronic low back pain) population using the pain beliefs questionnaire. Phys. Ther, 12,1615-1624 [2013].

6. A. Baird, D. Sheffield. The Relationship between Pain Beliefs and Physical and Mental Health Outcome Measures in Chronic Low Back Pain: Direct and Indirect Effects Healthcare, 4,58 [2016].

7. D.P Schwartz, DE DeGood, MS Shutty. Direct assessment of beliefs and attitudes of chronic pain patients. Arch Phys Med Rehabil, 66: 806-809 [1985]..

8. M.J. Simmonds, S. Kumar, E. Lechelt. Psychological factors in disabling low back pain: causes or consequences? Disabil Rehabil, 18:161-168 [1996].

9. L.C. Edwards, S.A. Pearce, L. Turner-Stokes, A. Jones. The Pain Beliefs Questionnaire: an investigation of beliefs in the causes and consequences of pain. Pain, 51: 267-272 [1992].

10. D.A. Williams, M.E. Robinson, M.E. Geisser. Pain beliefs: assessment and utility. Pain, 59:71-78 [1994].

11. P. Arnstein, M. Caudill, C.L. Mandle, A. Norris, R. Beasley. Self efficacy as a mediator of the relationship between pain intensity, disability and depression in chronic pain patients. Pain, 80:483-491 [1999].

12. J.A. Turner, M.P. Jensen, J.M. Romano. Do beliefs, coping, and catastrophizing independently predict functioning in patients with chronic pain? Pain, 85:115-125 [2000].

13. S.J. Linton, J. Vlaeyen, R. Ostelo. The back pain beliefs of health care providers: are we fear-avoidant? J Occup Rehabil, 12:223-232 [2002].

14. J.E. Jeffrey, N.E. Foster. A qualitative investigation of physical therapists' experiences and feelings of managing patients with nonspecific low back pain. Phys Ther, 92:266278 [2012].

15. G.L. Moseley. Reconceptualising pain acording to modern pain sciences. Physical Therapy Reviews, 12: 169-178 [2007]. 
16. S. Haldeman. Presidential address, North American Spine Society: Failure of the pathology model to predict back pain. Spine, 15: 718-724 [1990].

17. P. Kjaer, C. Leboeuf-Yde, L. Korsholm, J.S. Sorensen, T. Bendix. Magnetic resonance imaging and low back pain in adults: A diagnostic imaging study of 40 -year-old men and women. Spine, 30: 1173-1180 [2005].

18. A.M. Øien, S. Steihaug, S. Iversen, M. Råheim Communication as negotiation processes in long-term physiotherapy: a qualitative study. Scand J Caring Sci, 25: 5361 [2011].

19. T. Sloan, R. Gupta, W. Zhang, D, Walsh. Beliefs about the causes and consequences of pain in patients with chronic inflammatory or non-inflammatory low back pain and in pain-free individuals. Spine, 33, 966-972 [2008].

20. Ö. Sertel-Berk Kronik ağrı yaşantısı ve ağrı inançları: Ağrı İnançları Ölçeği’ nin Türkçe geçerlik ve güvenirlik çalışması. (Doktora tezi). [İstanbul Üniversitesi Sosyal Bilimler Enstitüsü, İstanbul 2006].

21. A.Ö. Birge, M. Mollaoğlu, Pain beliefs of patients and the nonpharmacological methods they use to manage the pain. Agri, 30(2):84-92 [2018].

22. B. Babadağ, G.B. Alparslan. Hemşirelik Öğrencilerinin Ağrı İnançları. Sted, 26(6):244250 [2017].

23. P. Van Wilgen, A. Beetsma, H. Neels, N. Roussel, J. Nijs. Physical therapists should integrate illness perceptions in their assessment in patients with chronic musculoskeletal pain; a qualitative analysis. Man Ther, 19:229-34 [2014].

24. R.W. Ostelo, S.G. Stomp-van den Berg, J.W. Vlaeyen, et al. Health care provider' attitudes and beliefs towards chronic low back pain: the development of a questionnaire. Man Ther, 8: 214-22 [2003].

25. J. Latimer, C. Maher and K. Refshauge. The attitudes and beliefs of physiotherapy students to chronic back pain. Clin J Pain, 20: 45-50 [2004].

26. D. Jones, J. Ravey and W. Steedman. Developing a measure of beliefs and attitudes about chronic non-malignant pain: A pilot study of occupational therapists. Occup Ther Int, 7: 232-45 [2000].

27. T. Overmeer, K. Boersma, C.J. Main, S.J. Linton. Do physical therapists change their beliefs, attitudes, knowledge, skills and behaviour after a biopsychosocial orientated university course? J Eval Clin Pract, 15: 724-32 [2009].

28. D.L. Rochman, M.J. Sheehan and R.J. Kulich. Evaluation of a pain curriculum for occupational therapists: experiences from a master's-level graduate program over six years. Disabil Rehabil, 35: 1933-40 [2013]. 